\title{
Long-term follow-up of trigger point injections for abdominal wall pain
}

\author{
Jose Nazareno $M D^{1}$, Terry Ponich $M D^{1,2}$, Jamie Gregor $M D^{1,2}$
}

\begin{abstract}
J Nazareno, T Ponich, J Gregor. Long-term follow-up of trigger point injections for abdominal wall pain. Can J Gastroenterol 2005;19(9):561-565.
\end{abstract}

OBJECTIVE: Abdominal wall pain (AWP) is a common yet often overlooked source of abdominal pain. Trigger point injections (TPI) into the abdominal wall have been tried in the past. Few studies have looked at the long-term outcome from these injections.

METHODS: A retrospective chart review was performed on 110 consecutive patients who received TPI for abdominal pain at the University of Western Ontario, London, Ontario. Outcomes from patients whose pain was due to AWP were determined. AWP was defined as fixed or localized pain and superficial or point tenderness (less than $2.5 \mathrm{~cm}$ diameter) or a positive Carnett sign (increased pain with tensing abdomen). The primary outcome was long-term efficacy of TPI. The number of diagnostic tests ordered to exclude AWP and the cost of investigating it were determined. Secondary analyses were done to determine if there were significant predictors of response to TPI.

RESULTS: Eighty-nine of 110 patients who received TPI met the criteria for AWP. In those who met the criteria for AWP, the average age was 42 years, $84 \%$ were female, and the average length of follow-up was 25 months. The primary outcome shows that, at follow-up, $77 \%$ had some or complete relief and $23 \%$ had no relief. An average of 4.3 diagnostic tests per patient were ordered to exclude other causes of abdominal pain. Secondary analyses show that meeting the criteria for AWP $(\mathrm{P}<0.0005)$, the absence of gastrointestinal symptoms $(\mathrm{P}<0.025)$, and an upper abdominal location of pain $(\mathrm{P}<0.025)$ were statistically significant predictors of a positive response to TPI.

CONCLUSIONS: This study demonstrates that TPI, in patients who meet criteria for AWP, are effective over the long term.

Key Words: Abdominal wall pain; Carnett sign; Trigger point injection

Information about the abdominal wall as a source of abdominal pain is scarce in the gastrointestinal (GI) literature. The first mention of abdominal wall pain (AWP) simulating visceral pain was in 1792, when Frank (1) published an article titled "Peritonitis muscularis". In 1926, Carnett (2), a surgeon, published a seminal article describing a syndrome he called intercostal neuralgia, which was caused by compromise of the abdominal cutaneous nerves. Since then, several studies, including a recent review by Srinivasan and Greenbaum (3), have attempted to provide better recognition of this inadequately acknowledged syndrome.

\section{Le suivi à long terme d'injections aux zones gâchettes de douleur de la paroi abdominale}

\begin{abstract}
OBJECTIF : Les douleurs de la paroi abdominale (DPA) sont une source courante mais souvent négligée de douleur abdominale. Des injections aux zones gâchettes (IZG) de la paroi abdominale ont déjà été tentées par le passé. Peu d'études ont évalué les conséquences à long terme de ces injections.
\end{abstract}

MÉTHODOLOGIE : Une analyse rétrospective des dossiers a été exécutée auprès de 110 patients consécutifs qui avaient reçu des IZG en raison de douleurs abdominales à l'université de Western Ontario de London, en Ontario. Les conséquences pour les patients souffrant de DPA ont été déterminées. Les DPA étaient définies comme des douleurs fixes ou localisées et une sensibilité superficielle ou localisée (moins de $2,5 \mathrm{~cm}$ de diamètre) ou un signe de Carnett positif (douleur accrue lorsque l'abdomen est tendu). La conséquence primaire était une efficacité à long terme des IZG. Le nombre d'examens diagnostiques demandés pour exclure les DPA et le coût de ces examens ont été établis. Des analyses secondaires ont été effectuées pour déterminer si des variables importantes expliquaient la réaction aux IZG.

RÉSULTATS : Quatre-vingt-neuf des 110 patients qui avaient reçu une IZG respectaient les critères de DPA. Ces patients avaient un âge moyen de 42 ans, 84 \% étaient des femmes, et la durée moyenne du suivi était de 25 mois. La conséquence primaire démontre qu'au suivi, $77 \%$ profitaient d'un soulagement partiel ou total et $23 \%$ n'étaient pas soulagés. Une moyenne de 4,3 examens diagnostiques avaient été demandés par patient pour exclure d'autres causes de douleur abdominale. Les analyses secondaires révèlent que le respect des critères de DPA $(\mathrm{P}<0,0005)$, l'absence de symptômes gastro-intestinaux $(\mathrm{P}<0,025)$ et le foyer abdominal supérieur de la douleur $(\mathrm{P}<0,025)$ constituaient des valeurs explicatives statistiquement significatives d'une réaction positive à des IZG.

CONCLUSIONS : La présente étude démontre que chez les patients qui respectent les critères de DPA, les IZG sont efficaces à long terme.

${ }^{1}$ Departments of Medicine and ${ }^{2}$ Gastroenterology, The University of Western Ontario, London Health Sciences Centre, London, Ontario
Correspondence: Dr Jamie Gregor, 375 South Street, Room 587, London Health Sciences Centre, South Street Campus, London, Ontario

N6A 4G5. Telephone 519-667-6843, fax 519-667-6620, e-mail jamie.gregor@lhsc.on.ca

Received for publication April 8, 2005. Accepted April 19, 2005 
nerve appears to be the most common. Applegate $(8,9)$ suggested that the anterior cutaneous nerve, which arises from the T7 to T12 intercostal nerves, makes two $90^{\circ}$ turns before reaching the skin. It usually slides unimpeded and buffered by fat in the neurovascular bundle. An entrapped nerve may either be pushed by intra-abdominal pressure or pulled by a scar. Other causes of AWP include hernias, hematomas or myofascial trigger points (3). Neuromas from scars (10), endometriosis in the abdominal wall (11), desmoid tumours (12) and intra-abdominal adhesions (13) have also been implicated. Finally, superficial lesions such as herpes zoster may mimic AWP.

In the present study, we investigated the long-term outcomes of patients who received trigger point injections (TPI) in a gastroenterology clinic for AWP. We determined the diagnostic tests that were ordered in its workup and the direct costs of investigating the pain. We also compared the outcomes in patients who met the criteria for AWP with those who did not meet the criteria. Finally, we determined whether any factors (including sex, GI symptomatology, radiation of pain, location of pain, type of injection and the presence of a scar) were predictors of response.

\section{METHODS}

\section{Patient selection}

A retrospective chart review was performed on 110 consecutive patients who received TPI performed by a university-based gastroenterology practice group at London Health Sciences Centre at the University of Western Ontario in London, Ontario. The patient list was generated from a list of all billed G384A (TPI) between January 1, 1995 and November 20, 2002.

\section{Definitions}

AWP was defined as pain that met the following criteria: fixed in location or very localized; AND superficial or point tenderness less than $2.5 \mathrm{~cm}$ in diameter or positive Carnett test. A positive Carnett test was defined as tenderness that increased with abdominal muscle tensing rather than tenderness that was made no worse with abdominal muscle tensing. These criteria were previously published and verified by Srinivasan and Greenbaum (3) as being good discriminators of AWP.

Upper GI symptoms were defined as nausea, vomiting, hematemesis, dysphagia, odynophagia, regurgitation, heartburn or waterbrash. Lower GI symptoms were defined as constipation, diarrhea, blood from the rectum, tenesmus or pain associated with a bowel movement. The presence of a scar was defined as a scar occurring in the immediate vicinity of the pain.

The duration of pain was defined as starting from the first instance it occurred and up until it was first injected. Follow-up was defined as the point from the first injection to when they were most recently seen. All of the follow-up occurred in clinic visits. No telephone follow-up was made.

Immediate relief of pain was defined as relief that occurred within two weeks of the initial injection. This was usually reported during the same visit as the injection itself. Late relief was defined as relief that occurred after two weeks of the injection. Both early and late relief were classified as being complete, some but not complete, or none whatsoever.

\section{Method of injection}

Bupivucaine $(0.25 \%$ to $0.50 \%)$ or lidocaine $(1.0 \%$ to $2.0 \%)$ was used as the local anesthetic. Betamethasone $(1 \mathrm{~mL})$ was used as the steroid. No more than $15 \mathrm{~mL}$ total volume was infiltrated at any one time. Anesthetic reinjections were offered to patients who had recurrence of pain.

\section{Diagnostic procedures and costs}

Procedures and tests were included only if chart review disclosed that they were performed to directly evaluate the abdominal pain. Tests were excluded if they were ordered for a different reason or a different symptom. The number of initial gastroenterology consultations as well as follow-up clinic visits scheduled specifically to follow the progress of the pain was added. The number of TPI performed was also added. To estimate the costs of the investigations and physician services, the 2003 Ontario Health Benefits Guide (14) was used. Other costs such as admissions to the hospital, facility fees, nursing fees, visits to the emergency room, visits to the family physician, and visits to other nongastroenterology specialists for evaluation of the pain were not included.

\section{Data analysis}

Discrete variables were calculated as counts and proportions and expressed as percentages. Continuous variables were measured as mean, standard deviation and median. $\chi^{2}$ testing of discrete variables was performed. The Fisher's exact test was used when any count was two or less to make the analysis more robust.

\section{Patient demographics}

\section{RESULTS}

Of 110 consecutive patients who received TPI, 89 patients met the defined criteria for AWP. In those who met the criteria for AWP, the mean age was 42 years (range 12 to 88 years). Eightyfour per cent of the patients were female. The mean duration of the pain was 23 months (range 0.25 to 180 months). The predominant locations of the pain were right hypochondrial (30\%), right iliac (25\%) and epigastric (19\%). Fifty per cent of patients experienced radiation of the pain, $73 \%$ of patients had some GI symptoms present and 39\% had a scar in the immediate vicinity of the pain (Table 1 ). Thirty-six per cent of the patients were reinjected. The number of reinjections ranged from one to 27.

Among the 21 patients who did not meet the criteria for AWP, the mean age was 41 years (range 17 to 76 years). Seventy-six per cent were women. The mean duration of the pain was 26 months (range 0.5 to 106 months). The predominant locations of the pain were umbilical (29\%), right iliac (23\%) and epigastric (19\%). Forty-eight per cent of patients experienced radiation of pain, $62 \%$ had some GI symptoms and $38 \%$ had a scar in the immediate vicinity of the pain. Twenty-nine per cent of these patients were reinjected.

\section{Diagnostic procedures and costs}

On average, 4.3 tests were performed per patient (Table 2). This included 93 ultrasound examinations, 71 esophagogastroduodenoscopies, 33 colonoscopies, 32 small bowel follow throughs, 30 computed tomography scans and 27 barium enemas. As well, 14 exploratory laparotomies were performed. An average of 3.3 follow-up visits were held per patient. The total cost was conservatively estimated to be $\$ 68,063$, or approximately $\$ 764$ per patient.

\section{Response to TPI}

Eighty-eight per cent of the patients were injected with a combination of local anesthetic and steroid, while $12 \%$ were injected with a local anesthetic alone. Eighty-nine per cent reported 
TABLE 1

Baseline patient characteristics

\begin{tabular}{|c|c|}
\hline \multicolumn{2}{|l|}{ Sex, \% } \\
\hline Male & 16 \\
\hline Female & 84 \\
\hline Age, mean years & 42 \\
\hline Duration of pain, mean months & 23 \\
\hline Length of follow-up, mean months & 25 \\
\hline \multicolumn{2}{|l|}{ Location of pain, $\%$} \\
\hline Right hypochondrial & 30 \\
\hline Epigastric & 19 \\
\hline Left hypochondrial & 7 \\
\hline Right lumbar & 2 \\
\hline Periumbilical & 3 \\
\hline Left lumbar & 1 \\
\hline Right iliac & 26 \\
\hline Suprapubic & 3 \\
\hline Left lumbar & 9 \\
\hline \multicolumn{2}{|l|}{ Gastrointestinal symptoms, \% } \\
\hline Yes & 73 \\
\hline No & 27 \\
\hline \multicolumn{2}{|l|}{ Radiation of pain, $\%$} \\
\hline Yes & 51 \\
\hline No & 49 \\
\hline \multicolumn{2}{|l|}{ Agent used, \% } \\
\hline Anesthetic only & 12 \\
\hline Anesthetic + steroid & 88 \\
\hline Steroid only & 0 \\
\hline \multicolumn{2}{|l|}{ Surgical scar present, $\%$} \\
\hline Yes & 39 \\
\hline No & 71 \\
\hline
\end{tabular}

some or complete early pain relief. The mean length of follow-up was 25 months (range 0.5 to 146 months). At follow-up, 77\% reported some or complete relief (Figure 1).

\section{Predictors of long-term pain relief}

Neither sex nor presence of radiation predicted response. Similarly, the addition of a steroid to local anesthetic did not alter the amount of relief obtained.

One of the strongest predictors of long-term relief was whether patients met the criteria for AWP (Figure 2). As mentioned, $77 \%$ of the patients who met the criteria for AWP experienced some or complete relief. However, only $35 \%$ of patients who did not meet the criteria experienced some or complete relief $(\mathrm{P}<0.0005)$.

The absence of GI symptoms was also a predictor of longterm relief (Figure 3). Ninety-five per cent of patients without GI symptoms experienced some or complete relief compared with only $71 \%$ of those with GI symptoms $(\mathrm{P}<0.025)$.

Also, the location of the pain was a predictor of relief (Figure 4). Eighty-seven per cent of patients whose pain was in the upper third of the abdomen (right hypochondrial, epigastric and left hypochondrial) experienced some or complete relief, while only $62 \%$ of those whose pain was in the lower two-thirds of the abdomen did $(\mathrm{P}<0.025)$.
TABLE 2

Investigations ordered to exclude other sources of pain

\begin{tabular}{lc}
\hline Test & Count \\
\hline Ultrasound & 93 \\
Esophagogastroduodenoscopy & 71 \\
Colonoscopy & 33 \\
Small bowel follow through & 32 \\
Computed tomography, abdomen & 30 \\
Barium enema & 27 \\
Upper gastrointestinal series & 23 \\
Hepatic dimethyl iminodiacetic acid cholescintigraphy & 20 \\
Endoscopic retrograde cholangiopancreatography & 14 \\
Laparotomy & 14 \\
Sigmoidoscopy & 7 \\
Gastric emptying study & 5 \\
Intravenous pyelogram & 5 \\
White blood cell scan & 5 \\
Meckel's scan & 4 \\
Magnetic resonance imaging & 4 \\
Small bowel enteroclysis & 386 \\
Magnetic resonance cholangiopancreatography & 3.3 \\
Cystoscopy & 2 \\
Total & 2 \\
\hline & 1 \\
Average & 1 \\
\hline
\end{tabular}

Finally, patients who had a surgical scar (76\%) experienced the same amount of relief as those without scars (78\%). However, they needed significantly more reinjections $(50 \%)$ compared with those without $(27 \%)$ surgical scars $(\mathrm{P}<0.05)$.

\section{DISCUSSION}

A number of treatments for AWP have been suggested. These include analgesics, topical anesthetic creams, massage, physical therapy, stretching and dry needling $(3,10,15)$. One of the more widely studied treatments consists of TPI into the most tender spot. There have been a number of case reports and studies looking at short-term relief but there are very few studies that have looked at long-term outcome from these injections (16-22). The majority of the studies show rates of long-term relief in the $70 \%$ to $80 \%$ range. For example, Bourne (18) (81\% complete or partial relief), Gallegos and Hobsley (20) (80\% complete or partial relief) and Greenbaum et al (21) (78\% having greater than 50\% relief) all reported similar rates of relief. However, there are some studies that have not fared as well. For instance, McGarrity et al (22) reported that only $35 \%$ of their patients experienced long-term relief. In our study, we achieved excellent response rates from TPI both in terms of short- (89\% complete or partial relief) and long-term (77\% complete or partial relief) outcome.

Each study had a slightly different patient base, different inclusion and exclusion criteria and use of the Carnett test, and different combinations of injected agents. One of the purposes of the present study was to try to determine which of these factors are important in predicting response. When faced with a patient with suspected AWP, knowing these factors would then help the physician select patients who would benefit the most from TPI. 


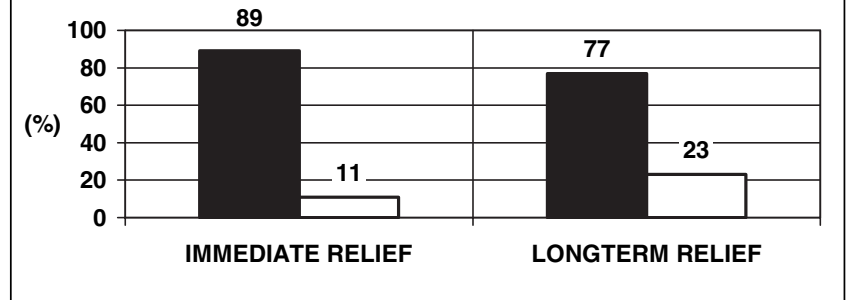

Figure 1) Primary outcome. Efficacy of trigger point injections immediately (less than two weeks) and over the long term (greater than two weeks). Black box: complete/some relief; white box: no relief; $n=89$

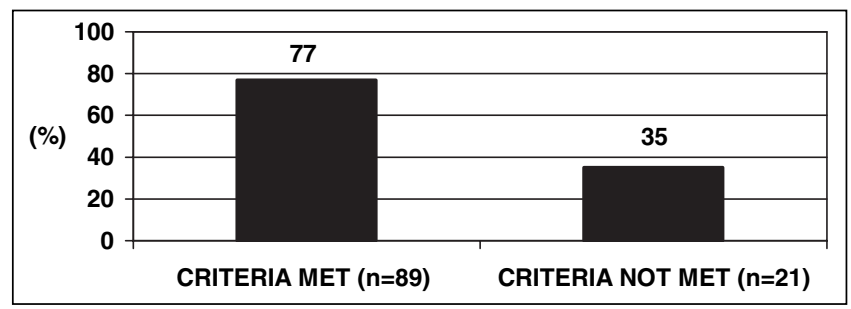

Figure 2) Predictor of response: Complete/some long-term relief based on meeting criteria for abdominal wall pain (AWP). Criteria for AWP: fixed in location or very localized; AND superficial or point tenderness less than $2.5 \mathrm{~cm}$ in diameter or positive Carnett test; $n=110$. $P<0.0005$

Meeting physical examination criteria for AWP was one such factor. In Carnett's original article, he suggested that "almost or quite as much" tenderness with abdominal wall tensing compared with the relaxed state was indicative of AWP. Subsequently, the use of the Carnett test has been examined. Thomson and Francis (7) found that only one of the 24 patients (4\%) with a positive Carnett's test admitted as an emergency was later found to have a visceral cause. Gray et al (23) later reported that five of 53 patients (9\%) with a positive Carnett's test had appendicitis. Other studies $(4,21)$ have shown similar false-positive rates. An argument could be made that these false-positive rates are too high for missing potentially lethal diseases. Greenbaum et al $(21,24)$ therefore modified the Carnett test to include additional criteria as outlined in the present paper, and it has been shown to have a sensitivity of $85 \%$ and specificity of $97 \%$. By comparison, the Carnett test alone was $78 \%$ sensitive and $88 \%$ specific. Not surprisingly, in our study, it was the patients who met these criteria for AWP that benefited the most from TPI.

The absence of GI symptoms was a predictor of response to TPI. The location of the pain was also a predictor of response. It seems as if pain located in the upper abdomen responds better than that in the mid to lower abdomen. One possible explanation for this is related to the ease of injecting the upper abdomen. The upper abdomen is generally less fatty than the lower abdomen. In our experience, we have found it easier to pinpoint and infiltrate trigger points in the upper abdomen, leading to better results.

One of the results that were a bit surprising was the lack of difference in efficacy when a steroid was added to the local anesthetic. It has been thought that steroids enhance the anesthetic effect (3) or provide more prolonged relief (10). There have been several hypotheses put forth as to how steroids may be of benefit. One of these is that steroids may reduce ectopic discharges from neuromas (25). Other hypotheses include

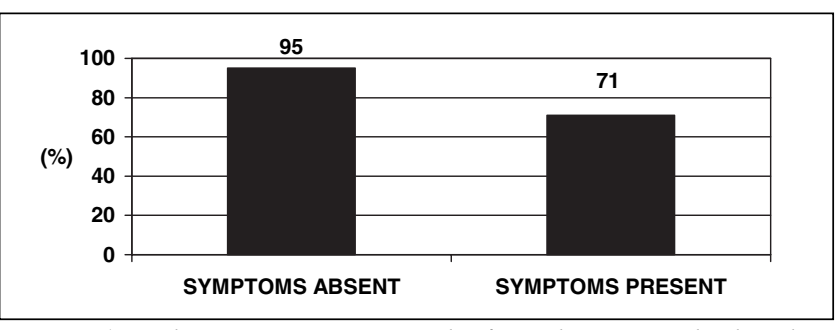

Figure 3) Predictor of response: Complete/some long-term relief based on presence of gastrointestinal (GI) symptoms. GI symptoms - nausea, vomiting, hematemesis, dysphagia, odynophagia, regurgitation, heartburn, waterbrash, constipation, diarrhea, blood from the rectum and/or tenesmus. $n=89 ; P<0.025$

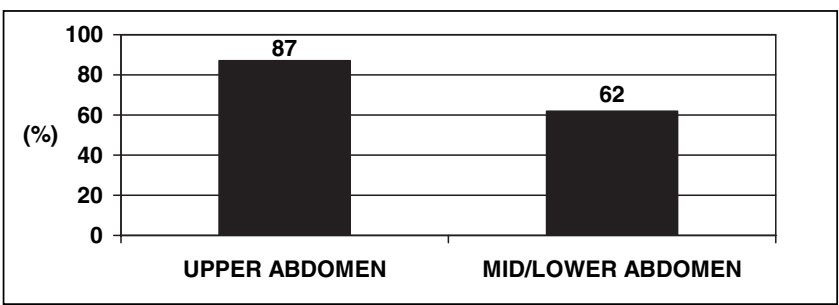

Figure 4) Predictor of response: Complete/some long-term relief based on location of pain. $n=89 ; P<0.025$

steroids acting as 'membrane stabilizers' (3) or acting as 'thinners' of connective tissue around painful nerve roots (10). A possible explanation for this lack of difference is that the main effect may be provided by the anesthetic which is thought to break the chronic pain cycle (3). Alternatively, the present study may not have had enough power to detect a difference that a larger study would have.

The economic costs of arriving at the diagnosis of AWP are not trivial. Similar to our findings, Hershfield (26) found that 100 patients with chronic AWP underwent an average of 4.18 diagnostic tests which were purely exclusionary. The cost of working up AWP has been estimated in the past to be anywhere from US\$680 (21) to US\$6,727 (27). Our estimate of $\$ 764$ is conservative in that it did not take into account visits to other specialists such as gynecologists, general surgeons and urologists, visits to the emergency department and hospital admissions. Hence, the actual total cost is far greater.

In summary, our study demonstrates that TPI, in patients who meet the criteria for AWP, are effective over the long term.

\section{REFERENCES}

1. Frank JP. Peritonitis muscularis. 1792. Cited in: Murray GR. An address on myofibrositis as a simulator of other maladies. Lancet 1929;1:113-5.

2. Carnett JB. Intercostal neuralgia as a cause of abdominal pain and tenderness. Surg Gynecol Obstet 1926;12:625-32.

3. Srinivasan R, Greenbaum DS. Chronic abdominal wall pain: A frequently overlooked problem. Practical approach to diagnosis and management. Am J Gastroenterol 2002;97:824-30.

4. Thomson WH, Dawes RF, Carter SS. Abdominal wall tenderness: A useful sign in chronic abdominal pain. Br J Surg 1991;78:223-5.

5. Rubio M, Gitlin MC, Lambiase LR. Abdominal wall pain as a cause of abdominal pain of obscure etiology. Am J Gastroenterol 1998;93:1740. (Abst)

6. Hall PN, Lee AP. Rectus nerve entrapment causing abdominal pain. Br J Surg 1988;75:917. 
7. Thomson H, Francis DM. Abdominal-wall tenderness: A useful sign in the acute abdomen. Lancet 1977;2:1053-4.

8. Applegate WV. Abdominal cutaneous nerve entrapment syndrome. Surgery 1972;71:118-24.

9. Applegate WV, Buckwalter NR. Microanatomy of the structures contributing to abdominal cutaneous nerve entrapment syndrome. J Am Board Fam Pract 1997;10:329-32.

10. Suleiman S, Johnston DE. The abdominal wall: An overlooked source of pain. Am Fam Physician 2001;64:431-8.

11. Wolf Y, Haddad R, Werbin N, Skornick Y, Kaplan O. Endometriosis in abdominal scars: A diagnostic pitfall. Am Surg 1996;62:1042-4.

12. Ward SK, Roenigk HH, Gordon KB. Dermatologic manifestations of gastrointestinal disorders. Gastroenterol Clin North Am 1998;27:615-36.

13. Lauder TD, Moses FM. Recurrent abdominal pain from abdominal adhesions in an endurance triathlete. Med Sci Sports Exerc 1995;27:623-5

14. Ontario Medical Association. Ontario Health Benefits Guide, 2003. <www.oma.org> (Version current at August 16, 2005).

15. Simons DG, Travell JG, Simons LS. Abdominal muscles. In: Simons DG, Travell JG, Simon LS, eds. Myofascial Pain and Dysfunction: The Trigger Point Manual, Vol 1: The Upper Half of Body, 2nd edn. Baltimore: Williams and Wilkins, 1999:940-70.

16. Mehta M, Ranger I. Persistent abdominal pain. Treatment by nerve block. Anaesthesia 1971;26:330-3.

17. Tung AS, Tenicela R, Giovanitti J. Rectus abdominis nerve entrapment syndrome. JAMA 1978;240:738-9.
18. Bourne IH. Treatment of painful conditions of the abdominal wall with local injections. Practitioner 1980;224:921-5.

19. McGrady EM, Marks RL. Treatment of abdominal nerve entrapment syndrome using a nerve stimulator. Ann R Coll Surg Engl 1988;70:120-2

20. Gallegos NC, Hobsley M. Recognition and treatment of abdominal wall pain. J R Soc Med 1989;82:343-4

21. Greenbaum DS, Greenbaum RB, Joseph JG, Natale JE. Chronic abdominal wall pain. Diagnostic validity and costs. Dig Dis Sci 1994:39:1935-41.

22. McGarrity TJ, Peters DJ, Thompson C, McGarrity SJ. Outcome of patients with chronic abdominal pain referred to chronic pain clinic. Am J Gastroenterol 2000;95:1812-6.

23. Gray DW, Dixon JM, Seabrook G, Collin J. Is abdominal wall tenderness a useful sign in the diagnosis of non-specific abdominal pain? Ann R Coll Surg Engl 1988;70:233-4.

24. Greenbaum D, Dawson F, Watson R. Chronic abdominal wall pain: A commonly but frequently overlooked disorder. Poster presented at the World Congress of Gastroenterology; August 26-31,1990; Sydney.

25. Devor M, Govrin-Lippmann R, Raber P. Corticosteroids suppress ectopic neural discharge originating in experimental neuromas. Pain 1985;22:127-37.

26. Hershfield NB. The abdominal wall. A frequently overlooked source of abdominal pain. J Clin Gastroenterol 1992;14:199-202.

27. Thomson C, Goodman R, Rowe WA. Abdominal wall syndrome: A costly diagnosis of exclusion. Gastroenterology 2001;120:A637. (Abst) 


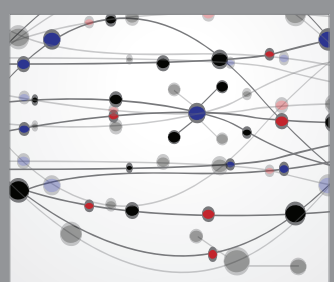

The Scientific World Journal
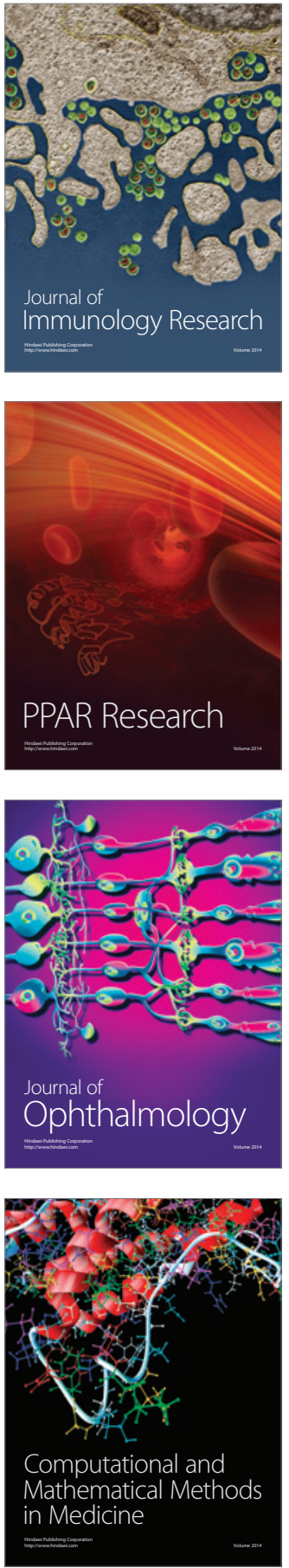

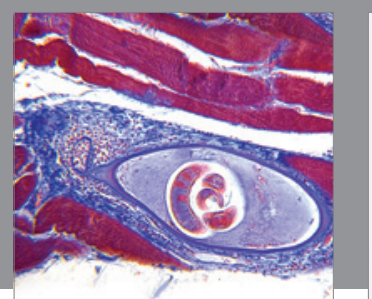

Gastroenterology Research and Practice

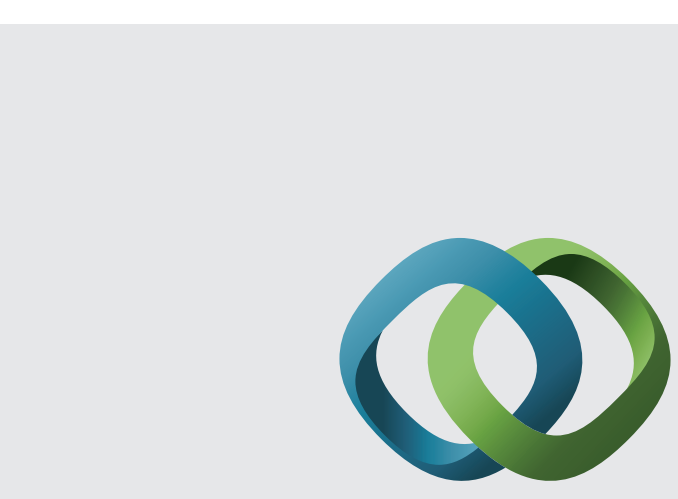

\section{Hindawi}

Submit your manuscripts at

http://www.hindawi.com
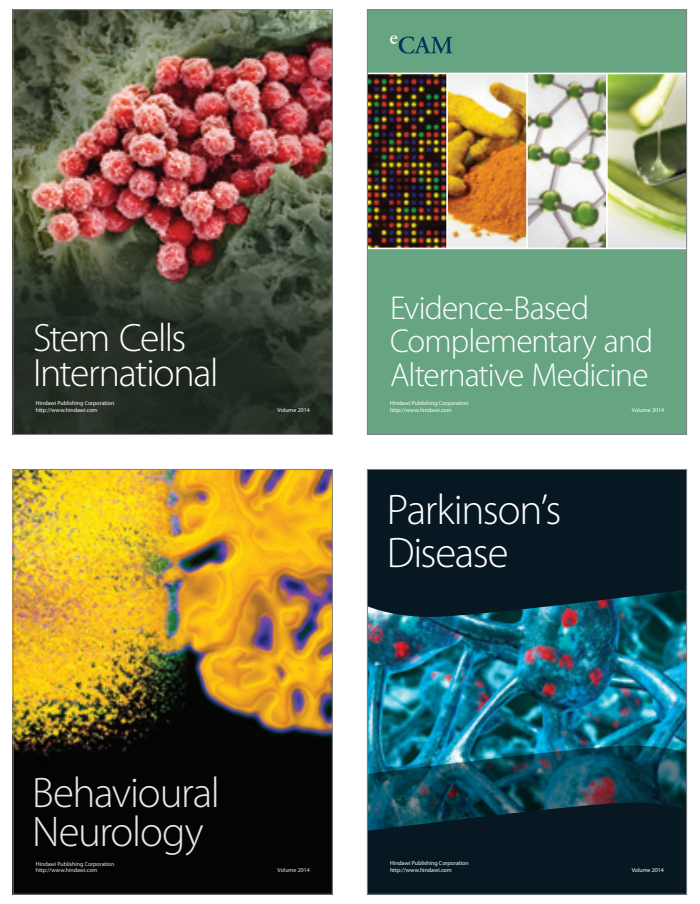
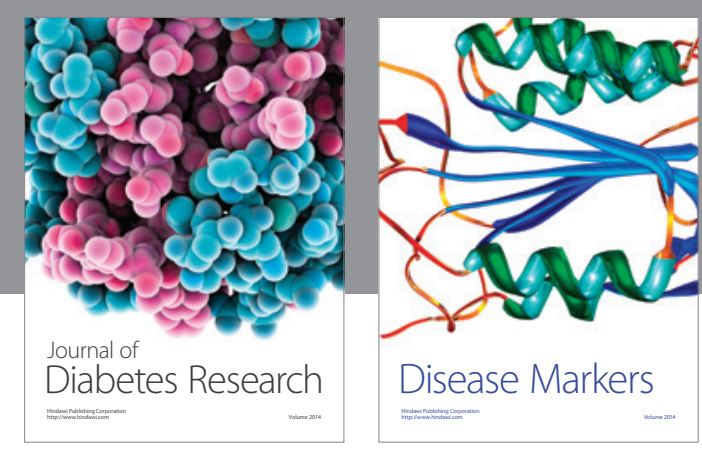

Disease Markers
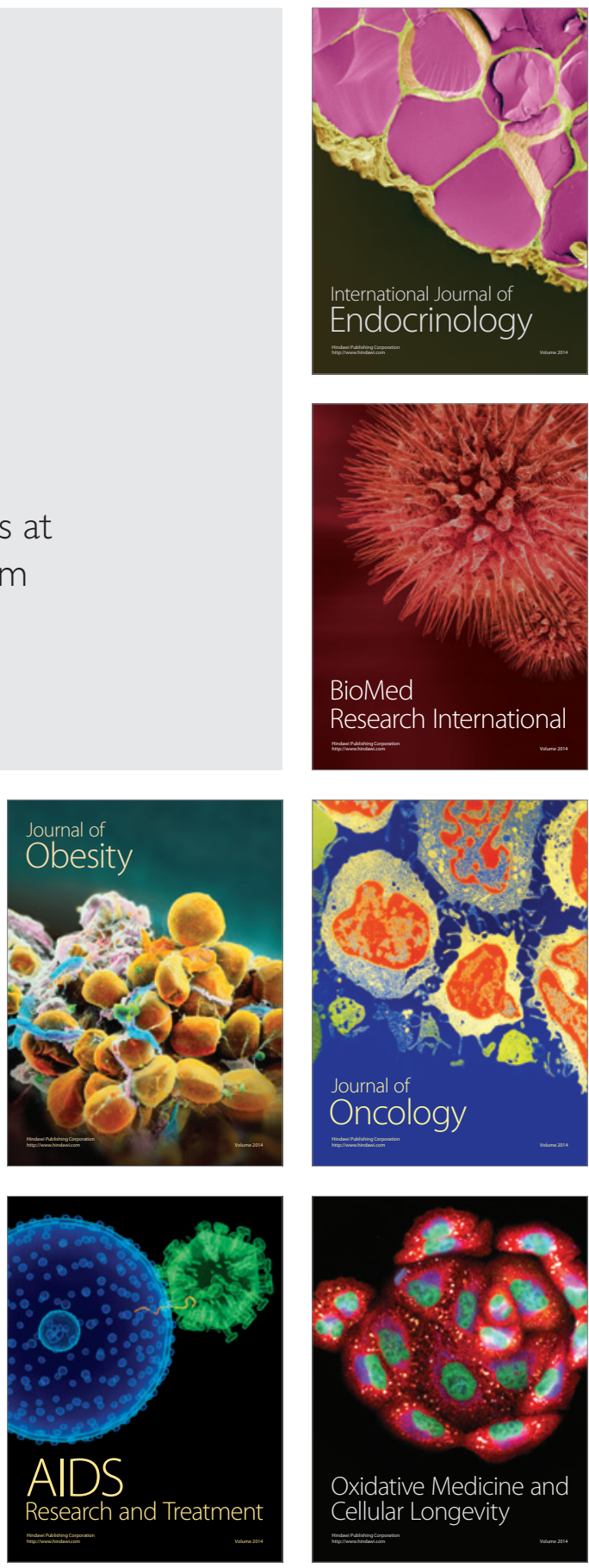